$1-1-2005$

\title{
Bearing the costs of human-wildlife conflict: The challenges of compensation schemes
}

\author{
Philip J. Nyhus \\ Colby College, pjnyhus@colby.edu \\ Steve A. Osofsky \\ Paul Ferraro \\ H Fischer \\ Francine Madden
}

Follow this and additional works at: https://digitalcommons.colby.edu/faculty_scholarship

Part of the Behavioral Economics Commons, Biodiversity Commons, Human Geography Commons, International and Area Studies Commons, Nature and Society Relations Commons, Other Ecology and Evolutionary Biology Commons, Other Economics Commons, Public Affairs, Public Policy and Public Administration Commons, and the Zoology Commons

\section{Recommended Citation}

Nyhus, Philip J.; Osofsky, Steve A.; Ferraro, Paul; Fischer, H; and Madden, Francine, "Bearing the costs of human-wildlife conflict: The challenges of compensation schemes" (2005). Faculty Scholarship. 15. https://digitalcommons.colby.edu/faculty_scholarship/15 
make appropriate management recommendations will be lacking in many conflict situations. Even if armed with rich scientific data, policy-makers must judge broad public approval for alternative removal programmes Without such approval, wildlife managers may lose full, flexible control.

No single prescription will be appropriate for all conflict situations Instead, the entire constellation of political, economic and aesthetic demands of affected human populations should dictate local and regional solutions (Treves and Karanth 2003). Therefore design of a control pro gramme requires stakeholder input, and consideration of the material and non-material values of the wildlife, stakeholders' perceptions of government intervention, views of the human role in nature, and rarity of the species in question.

Given uncertainty about stochastic causes of mortality in most large animal populations, we suspect that erring on the side of caution is the best way to maintain wildlife population viability for certain species. The prospects for coexistence of wildlife and people have improved in many parts of the world where wildlife eradication campaigns have been replaced with efforts to promote coexistence. Achieving this coexistence will ental technological innovation, including developing better non-lethal deterrent methods, more accurate identification of problem animals and conflict sites, and improved monitoring of the impacts of control programmes. It will also require negotiation to reach a compromise between people who demand the removal of all inconvenient or threatening species and those who demand protection for every wild animal.

\section{ACKNOWLEDGEMENTS}

We thank Rosie Woodroffe, Simon Thirgood, Luke Hunter and one anony: mous reviewer for their detailed and helpful contributions to this chapter. AT was supported by the Wildlife Conservation Society during manu script preparation. LN-T was supported by the Center for Applied Biodiversity Science-Conservation International and the University of Wisconsin-Madison. All opinions expressed in the chapter are only the authors' and we take responsibility for all errors.
Bearing the costs of human-wildlife conflict: the challenges of compensation schemes

PHILIP J. NYHUS, STEVEN A. OSOFSKY, PAUL FERRARO FRANCINE MADDEN AND HANK FISCHER

\section{INTRODUCTION}

As the cases in this volume vividly illustrate, human conflict with wildlife is significant - and growing - conservation problem around the world. The risk of wildlife damage to crops, livestock and human lives provides incentives for rural residents to kill wildlife and to reduce the quantity and quality of habitat on private and communal lands.

Recognition among conservationists that the cost of conserving large and sometimes dangerous animals is often borne disproportionately by farmers and others living closest to wildlife has spawned strategies to reduce this imbalance. One popular response is to compensate rural residents for the costs of wildlife damage. By spreading the economic burden and moderating the financial risks to people who coexist with wildlife, conservationists hope to reduce the negative consequences of human-wildlife conflict.

Few systematic efforts have been made to evaluate the efficacy of these programmes or the best way to implement and manage these schemes for endangered species (Sillero-Zubiri and Laurenson 200I). In this chapter, we build on our recent study (Nyhus et al. 2003) which asked whether compensation programmes really help endangered species in conflict with humans. We surveyed 23 international experts in large mammal conservation to learn about common pitfalls associated with running a compensation programme and the resources that managers need to succeed. Here, we also draw on additional published studies and reviews to explore the role of compensation in resolving conflicts between people and wildlife. We analyse the prospects and challenges of using these schemes in both developed and developing countries as part of a comprehensive suite of approaches to mitigate the effects of human-wildlife conflict on the long-term survival of Published by Cambridge University Press. $\mathrm{C}$ The Zoological Society of London 2005. 
endangered species. We also introduce the idea of performance payments and other alternatives to traditional compensation schemes.

\section{COMPENSATION IN PERSPECTIVE}

In their most common form, compensation schemes reimburse individuals or their families who have experienced wildlife damage to crops, livestock or property, or who have been injured, killed or physically threatened by wildife. A farmer who experiences wildife damage may receive compensation in the form of cash or in-kind assistance. Compensation can range from more than fair market value to just a fraction of the value of the lost crops or livestock.

Compensation programmes typically target single species or small groups of species. Payment for damage by large or predatory protected species is common. What or who is eligible for compensation may be narrowly defined. For example, compensation for damage by specific large predators may be limited to livestock owners following specified animal husbandry guidelines. Some programmes may target single species damaging specific crops, others may pay for any damage resulting from any protected species or from any species if the damage occurs in a prescribed area (Cozza et al. 1996; de Klemm 1996). Eligibility for compensation may depend on where an attack occurs, such as inside or outside a protected area, or upon officials' assessment of the danger to farmers of driving animals away from their crops or livestock.

State-sponsored efforts to manage human-wildlife conflict are not new. Historically, governments have used economic incentives to reduce conflict by supporting bounties to exterminate problem animals. The wolf (Canis lupus) in North America (Bangs et al., Chapter 2I) is just one example where bounties contributed to the successful eradication of an animal from much of its historic range. Many compensation programmes have been initiated after management and conservation efforts increased the size of diminished wildlife populations, and so many programmes are relatively recent in origin. (Wagner et al. I997).

Legal protection of endangered species can restrict the time-honoured practice of lethal control, yet may not provide precedent for state-sponsored compensation for wildlife damage. As de Klemm (1996) suggests, the issue boils down to the elimination of the right of farmers to protect themselves from damage from legally protected animals. The inability of farmers to kill certain species sets up conditions favourable for compensation, even if legal protection of wildlife has not made governments liable for damage.

In fact, in the USA, courts have historically viewed wildlife as res nullius (having no owner), thus limiting liability of the state (de Klemm I996). The
Box 7.I. Compensation and wolf recovery in the USA

\section{Hank Fischer ${ }^{\mathrm{I}}$}

Prospects for restoring wolves to Yellowstone National Park were grim in I984. But when William Penn Mott became Director of the US National Park Service, he gave me brilliant advice. "The single most important action conservation groups could take to advance Yellowstone wolf restoration would be to develop a fund to compensate ranchers for any livestock losses caused by wolves,' he said. 'Economics makes ranchers hate the wolf. Pay them for their losses and you'll buy tolerance and take away their only legitimate reason to oppose wolf recovery.'

Defenders of Wildlife made its first compensation payment in 1987 and by 1992 established a permanent fund to pay for verified livestock losses in the northern Rockies and later the Southwest. This was the first private compensation programme for wolves established in North America.

Here's how the programme works. If a rancher believes a wolf has killed his livestock, he contacts the appropriate government agency. A trained biologist, usually on the scene within 48 hours, investigates to determine whether wolves were responsible. If the investigator verifies that wolves killed the livestock, Defenders is notified. Defenders strives to get cheques to ranchers within two to four weeks of receiving verification of a loss. When ranchers were concemed about unverified losses, Defenders established a category for 'probable' losses, for which it compensates livestock producers at half the market value.

From its inception through 2002 , the Defenders programme paid over $\$ 270000$ to nearly 225 ranchers to compensate for 327 cows, 678 sheep and 34 other animals killed by wolves. Some feel this is a huge sum to pay for wolves, others feel it is a tiny price. But wolf experts agree that shifting economic responsibility for wolves away from ranchers and toward wolf supporters has created broader public acceptance for wolf recovery and reintroductions.

According to US Fish and Wildlife Service wolf recovery coordinator Ed Bangs, "The livestock compensation programme has made wolf recovery more tolerable to livestock producers and has made wolf recovery more easily attainable.'

'Hank Fischer developed Defenders of Wildlife's compensation programmes and managed them for nearly is years.

US federal government does not provide direct compensation for wildlife damage (Bangs and Shivik, 200I), leaving states to fill the void. Where government programmes are unavailable, non-governmental organizations have occasionally spearheaded compensation programmes, particularly for endangered species (see Box. 7.r).

\section{ECONOMICS OF COMPENSATION}

A major benefit attributed to compensation programmes is that they may increase tolerance of wildlife and promote more positive attitudes and 
support for conservation among people who live closest to endangered and dangerous animals (Wagner et al. 1997). When carried out effectively, compensation programmes raise awareness about community concerns and shift economic responsibility to a broader public. Compensation may result in a landowner giving a wild animal additional chances or result in discussions of how to prevent conflict in the first place. Conservation education and moral persuasion may be more effective in the presence of compensation. In the absence of effective compensation programmes, revenge killing or poaching may be more likely.

However, there is little quantitative evidence to support these claims. Although compensation programmes are conceptually appealing, their effectiveness in reducing local efforts to eradicate nuisance wildlife is largely unknown (for an exception see Box 7.I).

In a world of perfect information, establishing an effective compensation programme would not be difficult. However, the world of humanwildlife interactions is characterized by imperfect information. Thus, compensation proponents must struggle to verify that wildlife damage has occurred, to estimate its cost, to deliver payments quickly and efficiently over time and space, and to ensure that incentives created by the compensa tion programme do not make achieving the ultimate objective - maintaining or increasing endangered wildlife populations - more difficult. These tasks, discussed below, are the core elements of any compensation scheme.

\section{Verifying damage}

Verification is a vexing problem for many programmes because evidence of the wildlife that can cause damage, such as predator spoor, can disappear quickly. Even when investigated immediately, the true cause of damage may not be easy to ascertain. For example, it may be difficult to distinguish damage caused by different animals (Van Eerden I990; Olsen r991; Hötte and Bereznuk 2001). To address this uncertainty, there is a need for sound ecological research to quantify animal-inflicted damage and economic losses in relation to other sources of damage (e.g. Thirgood et al., 2000b), and for techniques to differentiate among different 'problem' animals, such as new DNA analyses that can even forensically differentiate individual animals (Ernest and Boyce 2000).

The problem of unverified losses remains one of the most critical challenges for many programmes. Research in Wyoming, USA, using radio-collared livestock found that for every verified livestock loss from grizzly bears (Ursus arctos), the equivalent of another two-thirds of an animal is never found, potentially resulting in under-compensation (Wyoming Game and Fish Department, unpubl. data 1996). The case of Norway provides an extreme example of this problem: in 200I, only $5 \%$ to 10\% of compensated sheep losses were actually documented kills by wild carnivores (Linnell and Brøseth 2003), a scenario which may represent overcompensation.

Endangered wildlife sometimes takes more than its share of the blame. For example, predation may not be the largest source of mortality among livestock (Kruuk 2002). Sutton et al. (2002) found that although elephants (Loxodonta africana) and other wildlife cause substantial crop damage in Namibia, domestic livestock damage to crops is much higher than that of any other animal (see also Naughton-Treves and Treves, Chapter I6). A survey respondent in Switzerland noted that sheep-farmers frequently claim that sheep that die or go missing have been killed by wolves and lynx (Lynx lynx). Yet, when researchers studied this problem, they found that the same numbers of sheep are lost in areas with and without large carnivores. These farmers, of course, have an incentive to attribute losses to carnivores. Unless they have private insurance, which most do not, they are only compensated for losses due to large carnivores - not lightning, falling rocks, or unidentified domestic dogs. These incentives lead to conflict between farmers and game wardens, who have to verify the cause of death, and can strain relationships with researchers, who may be summoned to make an expert judgement when verification is difficult (U. Breitenmoser pers. comm.). Outside verification is essential because self-reporting of wildlife damage may result in overestimates of damage by compensation seekers (Sekhar 1998) or fraudulent claims.

Although the problem of overstating losses is difficult, practitioners can draw from the economic research on the design of contracts that encourage people with private information to tell the truth (Wu and Babcock I996; Moxey et al. 1999). Accurate verification takes time, but delaying verification or having such high standards that few claims are verified can lead to hostility from farmers. In India, a respondent familiar with one statesponsored compensation programme reported that officials may take months to verify a wildlife attack, and unless it is a case of multiple killings, losses may not be verified at all. As a result, this respondent concluded, 'the actual payment of compensation is rather corrupt and whimsical'.

\section{Making payments}

Timely payment can help victims to get over their anger, and may reduce their incentives to retaliate against the animals that caused the damage, or to complain to neighbours or the media. Programmes self-reported to be effective (Nyhus et al. 2003) typically compensate quickly following verification, and strive to provide a transparent and fair claims process. A transparent 
process can be vital to avoid abuse, such as when a few individuals manipulate the system (Sillero-Zubiri and Laurenson 200r), and insufficient information about a programme can lead to frustration among participants (Wagner et al 1997). Programmes self-described as successful (Nyhus et al. 2003) also commonly separate the verification arm of the compensation scheme from the arm providing the actual payment.

Determining loss and compensation values can be a challenge because the value of livestock (or crops) may vary with age, size or reproductive status. For example, farmers may receive compensation for a young anima killed by a carnivore, but resent not receiving compensation for the value the animal could have provided if sold for meat or for breeding when mature Even when compensated monetarily, some farmers may perceive they are not receiving fair compensation for the trauma, time or hardships they face protecting their assets, or the emotional loss of losing their livestock (Kruuk 2002; Thirgood et al., Chapter 2). The programme in Switzerland described above addressed this by calculating the full potential market value of live stock lost to lynx and wolves, even if the animal killed was not yet mature. The State of Wyoming, USA, now pays more than market value for losses of livestock verified to be caused by grizzly bears to make up for the losses that cannot be verified or found. Programmes in France and Spain have adopted similar policies for bear-related compensation. In Norway, damage above average non-predation mortality is eligible for compensation if othe predator-caused mortality has occurred in the area, predators reside perma nently in the area, or the area has a history of chronic loss from predators (Linnell and Brøseth 2003).

Less successful programmes typically paid much less than market value (Nyhus et al. 2003). In Botswana, one programme reportedly paid out only about one-quarter the value of the livestock lost. In India, one state-run scheme reportedly set compensation at an even smaller fraction of the market value of each domestic animal. Expectations among local people about what the government could do increased, but human-wildlife conflic was not alleviated.

Human-wildlife conflict also leads to the loss of human life. Zhang and Wang (2003) report that while elephants (Elephas maximus) rarely lil people in the Simao region of China, the potential for such tragedy scare people and intensifies negative attitudes toward wildlife. Putting a value or a human life is both difficult and, according to some, immoral. Paying too little for a human death or injury may have no effect on reducing negative attitudes toward wildlife. Despite these obstacles, several nations compen sate for the loss of human life. In Zimbabwe, families of 21 victims killed in 200 t while protecting their fields from elephants were each paid Z\$I5000
( $\$ 273$ ) (The Sunday Mail 2002), and in Malaysia, the government recently established a fund to pay families RM5000 ( $\left.\sim \$_{1300}\right)$ for injuries and RM10000 for death resulting from wildlife (The Star 2003).

Ultimately, a compensation programme must ensure that local people are part of the overall management of the problem and participate in determining what constitutes appropriate compensation. A conservation programme manager in Botswana noted that attempting to 'buy' community compliance with conservation will not work unless decisions related to wildife and money are made by the communities themselves. Of course, participatory approaches are easier said than done. Rural residents have an incentive to inflate their claims and, unlike participants in a competitive commodity market, conservationists cannot simply walk away and find a more reasonable seller.

\section{Payments and sustainability}

Wildife damage is unlikely to disappear with time and thus a compensation programme must have a sustained source of sufficient funds. The annual cost of maintaining a compensation programme - particularly if damage is frequent and extensive - can be substantial and can range from a few thousand dollars for small programmes to more than a million dollars for regional multi-species programmes. In Pakistan, one non-governmental organization (NGO) spends approximately $\$ 2000$ annually on a snow leopard project and the Italian government has spent $\$ 2$ million on compensation for wolf, feral dog and bear damage.

The cost of compensation programmes is not limited to the payment for wildlife damage. Management of the programme and verification can involve major costs also. In Asturias, Spain, rangers devote an estimated 1000 person-days per year assessing wolf damage for an area of $5000 \mathrm{~km}^{2}$ with 200 wolves (Blanco 2003). As Karanth and Madhusudan (2002) note, the cost of administering schemes can be higher than the monetary value of the crops or livestock lost.

Funding for compensation schemes typically comes from public agencies (via taxes), non-governmental conservation organizations, private funds or fees paid by certain groups like hunters (de Klemm 1996). In some cases, compensation is in the form of live animals. For example, in Turkmenistan, the Worldwide Fund for Nature (WWF) purchased I9 6 sheep to provide a long-term source of compensation (Lukarevsky 2003).

As in any conservation initiative, stable long-term funding is essential to achieving success. Wagner et al. (1997) reported that six states or provinces in North America had to cancel programmes because of budget cutbacks or changing priorities. Programmes established when wildife populations are 
low and conflict is relatively rare may face problems if wildlife populations, and thus conflict, increase. Uneven distribution of wildlife damage incidents, as occurs with geese in the UK, can confound estimates of the amount of funds needed to sustain a programme, but such estimates are an important means of securing adequate funding (Hanley et al. 2003; Cope et al., Chapter II).

Incentives

Even in situations where rapid and accurate verification and adequate pay ments are possible, a successful compensation programme has to wrestle with three thorny issues related to incentives.

First, if compensation provides full insurance to rural residents against wildlife damage, but rural residents are able to influence the probability of loss (e.g. by using guard dogs for livestock), then a problem that economists call 'moral hazard' arises. Knowing that they will be compensated for wild. life damage, some individuals may be less likely to adopt new - or improve existing - management practices that would discourage conflict in the first place. Not only are residents less likely to improve their current methods but they may also reduce their current level of investment in management practices (e.g. they might graze animals closer to predator habitat). In the absence of incentives for rural residents to protect their assets, a permanent state of conflict is assured.

In some regions of Spain, farmers are compensated regardless of whether they leave their livestock unattended or they watch their livestock closely (Blanco 2003). A rational farmer might not bother to invest in costly methods of protecting his livestock. Participants who already use good management techniques may then criticize programmes when they are not compensated for the time and money they invest in good management practices, while others who take no action are fully compensated.

One solution to the moral hazard problem is to force farmers to act to reduce the risk of losses. This can be achieved by requiring participants to adopt observable risk-reducing investments before they are eligible for compensation. For example, payment may be denied to those with poor practices (e.g. not putting livestock in enclosures at night) or to those who do not follow guidelines for damage prevention after their first reported ind: dent. The key aspects of these requirements are that they must be observable and effective at reducing risk. One problem with requiring specific invest. ments, however, is that farmers may know better than outsiders how best to reduce wildlife damage. In the absence of consultation, external pressure may do little to alleviate the costs of moral hazard.

Another way to reduce moral hazard is to force rural residents to bear some of the risk by establishing a deductible (i.e. the resident pays part of any loss). Deductibles encourage farmers or ranchers to protect their crops and livestock. In effect, many compensation programmes already do this by not paying the full value of damages. However, risk-sharing may not be acceptable to farmers who resent incurring substantial costs on behalf of others who value the wildlife. Even without such beliefs, residents who incur a cost from wildlife damage may still have incentives to kill wild animals. Furthermore, mandatory changes in livestock husbandry that are not perceived to be worth the cost incurred will simply not be implemented (de Klemm I996). In a study of the willingness to pay of Namibian households for an electric fence to guard against wildlife damage, Sutton et ai. (2002) concluded that most households would never choose to invest in electric fences unless they were heavily subsidized. Of course, for compensation to be an option of choice, logical and sustainable subsidies should not be considered anathema. Ultimately, any costs from moral hazard should be weighed against the possible conservation benefits of a compensation programme.

A second incentive problem arises from compensation's role as an agricultural subsidy. Compensation increases the net returns from agricultural production and thus may provide incentives to convert natural habitat to agriculture. In a theoretical simulation, Rondeau and Bulte (2003) found that under certain assumptions (e.g. free trade, open-access land, price effects from compensation), compensation had a negative effect on wildlife. Furthermore, as a subsidy, compensation can delay the exit from farming by individuals who ought to exit (because the activity is not profitable) and encourage entry by those who, in the absence of compensation, would not farm. In less economically developed countries, compensation programmes might attract outsiders hoping to benefit - a 'magnet effect' - and ultimately increase the number of people exposed to wildlife damage. Ensuring that compensation is not available to unsanctioned new settlements and enforcing land-use agreements (e.g. keeping protected areas from being turned into agriculture) might be ways to address this problem.

Finally, cash itself can have undesirable effects. An influx of funds can generate conflict within communities or among communities and conservation practitioners. Such conflict is likely if programmes are not transparent or if perceived distribution of funds is not equitable.

\section{Private insurance}

To manage compensation programmes more efficiently and to sustain them over time, conservationists have looked at the insurance industry as a model. Several countries in Europe have used such an insurance-based approach (de Klemm I996; Fourli 1999; Blanco 2003). 
In most situations, however, an unsubsidized, purely private system of insurance is not viable. The difficulties associated with verifying damage and farmer investments in damage avoidance are substantial and thus lead to problems of fraudulent claims, moral hazard and adverse selection. Adverse selection occurs when insurance agents cannot differentiate high-risk from low-risk clients and thus cannot provide insurance to low-risk clients at a reasonable price. For example, a study of the Sariska Tiger Reserve in Rajasthan, India (Sekhar 1998), found that villagers experienced on average a loss from wildlife depredation of Rs.370 while the annual premium to insure livestock would amount to approximately Rs.rr68. This was in part because a small number of households experienced considerable damage while a larger percentage experienced slight or no damage.

Even if private insurance could be made available, rural residents ma view it as too expensive given their perceptions of the likelihood of damage, their limited budgets and their access to alternative means of "insurance (e.g. poisoning animals). In a contingent valuation survey of households living near wildlife in Zimbabwe (Muchapondwa n.d.), r3r households hada zero willingness to pay for insurance and the mean willingness to pay for insurance for the remaining 439 households was Z \$2I5 ( $\sim 4$ ) per year - too low for a viable private insurance market. Furthermore, even if insurance was affordable, many would be unwilling to finance compensation for damages caused by wildlife perceived to be the state's responsibility. Thus successful implementation of private insurance may require subsidization either by a government agency, an NGO or members of a community no affected by wildlife damage (e.g. see Miquelle et al, Chapter I9).

Project Snow Leopard in Pakistan (Hussain 2003) claims to have over come some of these problems by relying on community participation and an innovative financial design. Farmers pay premium contributions to community-managed fund per head of livestock. A second fund, operated jointly by the community and Project Snow Leopard, generates income from ecotourism. The committee verifies kills and makes compensation recom mendations. Claims that exceed the claimant's accumulated premium amount are paid from the second fund. Biological surveys suggest snow leopard (Uncia uncia) populations are stable or increasing in the area, bu without a control area it is difficult to know whether this is a direct result of the compensation programme.

\section{MEASURING SUCCESS}

Documenting and defining the success of any conservation initiative can be a challenge. The goal of many compensation programmes is to increase tolerance for wildlife, but they may not actually eliminate conflict from occurring in the first place (Klenzendorf 1997; Wagner et al. 1997). Even when compensated, farmers may continue to kill wildlife illegally (Kruuk 2002, Naughton-Treves et al. 2004). There is also a risk that people will be more frustrated at the failure of an inadequate compensation programme orcessation of a successful one than if none had been in place at all (Wagner et al. 1997).

Thus, despite many attempts to implement compensation schemes of different kinds, little empirical evidence of their success or failure is available. Many programmes cannot objectively quantify the impact they are having on people's attitudes or the impact on the wildlife populations of conservation interest. Ultimately, more rigorous methods to evaluate the success of compensation schemes are needed, and managers should be encouraged to build into their programmes appropiriate evaluation measures that are ideally linked to the conservation status of the 'problem animal. Comparative assessments of local attitudes, as well as of the health and size of target wildlife population(s) before and after a programme has started, are sorely needed. Assessments of the number of animals of conservation interest killed in retribution for attacks or via illegal harvesting might be additional indicators, but it is notoriously difficult to monitor such retaliatory, illegal killing because it is often carried out clandestinely. Such assessments are further complicated by the many other factors that influence wildife numbers, such as weather or disease.

\section{ALTERNATIVES TO COMPENSATION}

The logic of compensating victims of wildlife damage is appealing, but conservationists, wildlife managers and even some recipients of compensation question whether it is the most effective and efficient use of scarce conservation funds. Alternatives, such as tourism or trophy-hunting, may potentially provide better investments in time, money and results (see Walpole and Thouless, Chapter 8, and Leader Williams and Hutton, Chapter 9 , for discussion of these issues). In some circumstances, alternative methods such as building wildife barriers or providing additional habitat may be more cost-effective than depending on individual farmers to adequately protect their farms. In a theoretical analysis of wildlife damage in high-income nations, Dyar and Wagner (2003) show that purchasing land to increase the amount of habitat between wildlife and crops/livestock can be more efficient than compensation.

Karanth and Madhusudan (2002) argue that just modifying human or animal behaviour ultimately does not address the root cause of the problem. 
They suggest that in some situations, such as where high densities of people and potentially lethal animals like tigers (Panthera tigris) coexist, and where voluntary resettlement of communities from enclaves within protected areas is possible, preventive spatial separation of people and wildlife may be the most cost-effective and practical solution.

Compensation, if available, is typically just one part of a larger humanwildlife conflict management strategy. In the western USA, lethal control remains a central part of management plans for wolves and bears (e.g. see Bangs et al, Chapter $2 \mathrm{x}$ ). Compensation may result in a landowner giving a large carnivore additional chances or encourage discussions of how to prevent conflict, but lethal control may ultimately still be used. Although the popularity of compensation programmes has been driven in part by the perceived ineffectiveness of education and moral persuasion, well-targeted participatory information campaigns may still be an effective use of scarce funds.

\section{Performance payments}

Rather than compensate rural residents for wildife damage, practitioners may want to consider making payments that are conditional on wildife abundance (Ferraro and Kiss 2002). In this approach, payments are tied to wildlife populations (e.g. for every elephant that exists in the district, com munities are paid $\$ x$; for every wolf den on a landowner's property, the landowner is paid $\$ Y$ ). A good example of this approach comes from Sweden, where Sami reindeer herders are paid for successful wolverine (Gulo gulo) dens within their areas (Swenson and Andrén, Chapter 2o), Similarly, farmers in Scotland are paid to maintain protected populations of geese on their land (Cope et al., Chapter II).

Although this approach has been most frequently used for habitat protection, it may be amenable to wildlife protection in situations in which wildife populations can be monitored (e.g. Musters et al. 200r) Unlike the damage compensation approach, the payment does not decrease a farmer's incentive to reduce the probability of damage. Instead, rural residents would have an incentive to adopt whatever mechanisms (includ ing doing nothing) are most cost-effective to reduce the amount of damage that wildlife imposes on their assets. Furthermore, performance payments do not increase the profitability of agriculture and thus, unlike damage compensation, do not increase the incentives to expand agriculture (the) may in fact provide disincentives).

Payments tied to wildlife abundance could also improve the welfare of rural residents by diversifying the household portfolio and reducing household exposure to risk. If agricultural production is relatively more variable than the wildlife populations to which performance payments are tied, then risk-averse farmers would be willing to accept lower relative returns from the wildlife payments in return for the payments' ability to reduce risk.

The performance payment approach, however, suffers from many of the same constraints faced by more traditional compensation schemes. Timely and accurate verification is still necessary, but instead of verifying damage, practitioners have to verify population size and changes over space and time. Other challenges include devising the rules for payment (e.g. is payment tied to a population estimate from a given method? do payments change linearly or non-linearly from a baseline estimate?), determining the appropriate payment levels, and deciding whom to pay. A performance payment approach must determine how to differentially pay residents according to their (unobservable) costs from living with wildlife. In the case of wideranging wildife, to whom should go the rewards for the protection of a particular animal? In some cases, such as paying for animal nesting sites, payments can be targeted at the household level; in other cases, such as paying conditionally on the population abundance of a species in a given area, payments might best be channelled to community-level benefits (e.g. reduced taxes or funds for schools and health clinics). A community-level payment is not necessarily undesirable because such payments may induce strong peer pressure effects on individuals: if one person kills an animal, this person has reduced the benefits that everyone in the community receives. Local people often have better information for monitoring their own members, but frequently have little incentive to do so. Practitioners can draw from research on designing incentive systems in situations in which one cannot monitor every individual's actions and thus must resort to rewarding and penalizing individuals as a group (e.g. Segerson 1988).

Despite the potential advantages of a performance payment approach in mitigating human-wildlife conflict, thus far there have been few economic analyses like the wolverine example cited above, or field experimentation to guide practitioners in implementing such an approach. Our intention in lighighting performance payments is simply to encourage researchers and practitioners to think more deeply about the potential of such an approach as an alternative to damage compensation, and to experiment with it in the field.

\section{CONCLUSION}

Human-wildlife conflict is an important threat to the survival of many species and requires innovative, practical and cost-effective solutions. Compensating farmers for damage caused by wildife has been tried as 
one such solution with mixed success around the world. By shifting the economic burden away from local people, at least in part to the broader public that wants to see these species conserved, compensation supporters believe it encourages constructive engagement by the people most closely tied to the future of the world's large, dangerous and endangered species.

Unfortunately, the issues surrounding such conflict are typically a com plex mix of behaviour (human and wildlife), ecology, socio-economics politics and geography - making the resolution of these conflicts extremely difficult. While there appear to be general guidelines that can aid wildlife managers in implementing effective compensation schemes, it is important to be sensitive to and to incorporate site-, species- and culture-specific issues.

Key determinants of success for compensation schemes typically include the accurate and rapid verification of damage, prompt and fair payment embedded in a transparent process, a long-term source of funding capable of responding to variations in damage over time, clear rules and guidelines that link payment to sound management practices, an appreciation of the cultural and socio-economic context, and an ability to actively monitor the wildlife population of interest.

In many areas of the world, the constraints to implementing successful compensation schemes are formidable. Corruption inhibits transparency Insufficient funding precludes fair payment. Inadequate staff and training impede accurate verification. Awareness of these pitfalls may help practi tioners to find workable solutions. Without such solutions, rural residents living near wildlife will continue to have considerable incentives and moti. vation to kill problem animals and to convert wildlife habitat.

Ultimately, compensation is only one tool in the human-wildlife conflict mitigation toolbox. To work most effectively, it needs to be part of a com. prehensive approach that includes proactive measures to prevent conflict in the first place, options to control offending animals and incentives to change land-use practices.

Several alternative approaches may provide opportunities for further testing. Lessons from the private insurance industry may help practitioners to more effectively estimate demand for and total costs of a programme over time. A performance payments approach, more frequently used for habitat protection, may sidestep some of the constraints, like moral hazard, faced by standard compensation programmes. Linking incentives to wildife abundance may have positive effects on the welfare of rural residents as well by diversifying their sources of income. Regardless of which approach, of combination of approaches, is used, it is clear that much remains to be learned about the effectiveness of using economic incentives to reduce the negative impact of human-wildlife conflict. The ultimate measure of a compensation scheme's effectiveness, as for any conservation tool designed to reduce human-wildlife conflict, is whether it keeps fewer tigers, elephants or gorillas (Gorilla gorilla) from being killed. But in most situations today we do not know if this is happening, and we have no way to compare whether the approach used was the best or most cost-effective strategy.

There appears to be a clear need for carefully designed, empirical research on the use of compensation payments to achieve conservation goals. In particular, studies with adequate controls are sorely needed. For example, it would be desirable to compare villages in similar areas that do or do not have access to compensation, to compare communities where compensation is paid at below- or above-market rates, or to explicitly compare traditional compensation schemes to an incentive-based performance payment approach. Practitioners would benefit from well-planned research on the joint effectiveness of several strategies aimed at reducing humanwildlife conflict. A publicly accessible database that would permit a transparent comparison of true costs and true benefits of various approaches could be a powerful step in this process.

Compensation programmes, under certain circumstances, may provide one component of an effective response to human-wildlife conflict, particularly when endangered species are the main 'offender' and lethal control is not a desirable option. However, if carried out with inadequate attention to certain key factors, these schemes can be a waste of resources destined to do more harm than good.

\section{ACKNOWLEDGEMENTS}

This chapter was based in part on an article that appeared in Conservation in Practice (2003) 4 (2) 37-40. We gratefully acknowledge the assistance we have received from Alistair Bath, Joshua Ginsberg, Ginette Hemley, Richard Hoare, Rodney Jackson, Sybille Klenzendorf; Caroline Mitten, Lisa Naughton-Treves, Judy Mills, Paul Paquet, Christine Rastas, John Seidensticker, Mingma Sherpa, Barry Spergel, Gail Carlson and all of those survey respondents from around the world who were willing to share their experiences, good and bad, regarding compensation schemes with us. 